\title{
Human perspective on cash to accrual based accounting system in Malaysia
}

\begin{abstract}
Cash-based accounting is a major accounting method that recognizes revenues and expenses at the time physical cash is actually received or paid out. The technical professional issue is that the accounts receivable and accounts payable are not shown in the balance sheet and they do need a type of ñauditò in order for a financial statement to be produced and errors abound in these reports. Furthermore, there is no inventory appearing on the balance sheet with cashbased accounting. This resulted in apparent potential human errors on work-in-process reports. Therefore, this study focuses on the need of change management to develop the human capital capability by looking at the perceptions, acceptance and capabilities of the clients and employees who are involved directly and indirectly with the government accounting process. The analysis showed the successful implementation of accrual-based accounting whereby greater emphasis needs to be placed by the government in ensuring the acceptance of the new system by clients and employees.
\end{abstract}

Keyword: Accrual based accounting; Change management; Perceptions; Acceptance; Capabilities 